\title{
Correction to: Flash glucose monitoring and automated bolus calculation in type 1 diabetes treated with multiple daily insulin injections: a 26 week randomised, controlled, multicentre trial
}

\author{
Anna Lilja Secher ${ }^{1}$ (I) - Ulrik Pedersen-Bjergaard ${ }^{2,3}$ (1) Ole L. Svendsen ${ }^{3,4} \cdot$ Birthe Gade-Rasmussen $^{5}$. \\ Thomas Almdal $^{3,6} \cdot$ Linda Raimond $^{1}$ • Dorte Vistisen ${ }^{1} \cdot$ Kirsten Nørgaard $^{1,3}$ (I) \\ Published online: 15 November 2021 \\ (C) Springer-Verlag GmbH Germany, part of Springer Nature 2021

\section{Correction to: Diabetologia} \\ https://doi.org/10.1007/s00125-021-05555-8
}

The footnote for Table 2 incorrectly stated the data were median (IQR) but should have reported the data as mean (95\% CI). The table footnote in the original article has been corrected.

Publisher's note Springer Nature remains neutral with regard to jurisdictional claims in published maps and institutional affiliations.

The online version of the original article can be found at https://doi.org/ $10.1007 / \mathrm{s} 00125-021-05555-8$

Anna Lilja Secher

anna.elisabet.lilja.secher@regionh.dk; anna.lilja.secher@gmail.com

1 Steno Diabetes Center Copenhagen, Gentofte, Denmark

2 Department of Endocrinology \& Nephrology, Nordsjællands Hospital, Hillerød, Denmark

3 Faculty of Health and Medical Sciences, Copenhagen University, Copenhagen N, Denmark

4 Department of Endocrinology, Bispebjerg and Frederiksberg Hospital, Copenhagen NV, Denmark

5 Department of Endocrinology, Amager and Hvidovre Hospital, Hvidovre, Denmark

6 Department of Endocrinology PE, Rigshospitalet, Copenhagen $\varnothing$, Denmark 